\title{
Burn surgeons in South Africa: A rare species
}

\author{
N L Allorto, ${ }^{1}$ MMed, FCS (SA); S Zoepke, ${ }^{2}$ Medical Student; D L Clarke, ${ }^{1}$ MMedSci, FCS (SA), MPhil, MBA, PhD; \\ H Rode, ${ }^{3}$ MMed, FRCS (Edin), FCS (SA) \\ ${ }^{1}$ Department of Surgery, Pietermaritzburg Metropolitan Hospital Complex and School of Clinical Medicine, College of Health Sciences, \\ Nelson R Mandela School of Medicine, University of KwaZulu-Natal, Durban, South Africa \\ ${ }^{2}$ School of Medicine, Faculty of Health Sciences, University of Pretoria, South Africa \\ ${ }^{3}$ Department of Paediatric Surgery, Red Cross War Memorial Children's Hospital and Faculty of Health Sciences, University of Cape Town, \\ South Africa
}

\section{Corresponding author: N L Allorto (nikkiallorto@gmail.com)}

\begin{abstract}
Background. The high burden of burn injuries in South Africa (SA) requires surgeons skilled in burn care. However, there are few dedicated burn surgeons and properly equipped units or centres.

Objectives. To quantify the involvement of surgeons in burn care in SA hospitals, identify factors that attract surgeons to pursue burn care as a career and deter them from doing so, and understand the challenges of hospitals treating burn patients around the country.

Methods. This was a prospective, qualitative study. Questionnaires were handed out at the South African Burn Society Congress in September 2013 and a trade symposium in March 2014.

Results. One hundred questionnaires were handed out, and there was a $70 \%$ response rate. Twenty-six (39\%) of the respondents had a specialist surgical qualification. Only half the units had registrars (48\%) and interns (51\%) on their staff. Only $30 \%$ of the respondents were dedicated to burn care alone, the majority being involved on a part-time basis. The most common factor respondents suggested was needed to recruit future burn care providers, cited by $76 \%$, was better facilities and resources. Other factors included training and skills development (59\%), subspecialist training (55\%), development of a diploma in burn care (52\%), development of research (52\%) and healthcare worker psychological support (45\%).

Conclusion. We have demonstrated that current workforce resources for burn care are inadequate, the major deficit being lack of training and the resource-restricted environment. This survey provides basic information towards workforce planning, which can be used to inform the necessary strategic decisions.
\end{abstract}

S Afr Med J 2016;106(2):186-188. DOI:10.7196/SAMJ.2016.v106i2.9954

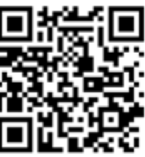

Access to quality burn care in Africa is limited, and systems that do exist struggle with financial restraints, large numbers of patients and acute shortages of adequately trained staff and facilities to render burn

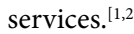

An acceptable standard of care can only be achieved with a fundamental investment in burn facilities and adequately trained staff. It is estimated that in South Africa (SA), which has the second largest economy in Africa, $3.2 \%$ of the population sustain a burn injury each year. The majority of these burns are minor and moderate (1.6 million injuries), $<10 \%$ being severe (3 200 injuries) and needing specialised care. However, admission numbers collected from burn units around the country show that there are in fact 8800 admissions per year. Poorly managed burns result in high morbidity and an increased number of burn-related deaths. Currently there are 23 burn 'units' in $\mathrm{SA}$, with a large variation in leadership, capacity and functioning. All can generally render acute emergency care, with a limited number rendering comprehensive care. The shortage of burn and trauma specialists is not unique to SA, shortages in general and specialist staff being reported in both high- and low-income countries. ${ }^{[3-6]}$

In order to align with the South African Burn Society's goal of improving burn care across the country, the workforce deficit needs to be addressed. Workforce planning is an essential part of capacity building and is the systematic process that identifies the current deficits and enables implementation of gap reduction strategies in order to overcome the barriers to achieving the defined goals. The purpose of this study was to investigate and quantify the involvement of medical personnel/surgeons in burn care in SA hospitals and to identify factors that attract or deter colleagues from entering the field of burn care as a career. This information is crucial to strategic planning for the future.

\section{Methods}

This was a prospective, qualitative study. Questionnaires were distributed at the SA Burn Society Congress in September 2013 and at a burn symposium in March 2014. Questions included information concerning the respondents' training, working environment, experience of staffing and time allocated to burn care, and their personal opinions regarding motivation to become involved, or not, in burn care. Doctors were asked to answer these questions anonymously and voluntarily. The data were collated into a Microsoft Excel spreadsheet for descriptive statistical analysis. The questionnaire is attached as Appendix 1.

\section{Results}

\section{Demographics}

One hundred questionnaires were handed out, and there was a 70\% response rate. Fifty $(71 \%)$ of the respondents were male, and the majority (69\%) were between 30 and 49 years of age. Fig. 1 illustrates the age distribution of respondents. The majority had been involved in burn care for 5 - 10 years (36\%) and $11-20$ years (31\%), with $16 \%$ involved for $<5$ years, $14 \%$ for $21-30$ years and $3 \%$ for $>30$ years.

\section{Training}

Twenty-six respondents (37\%) had a specialist surgical qualification. This study did not distinguish between specialists in training 


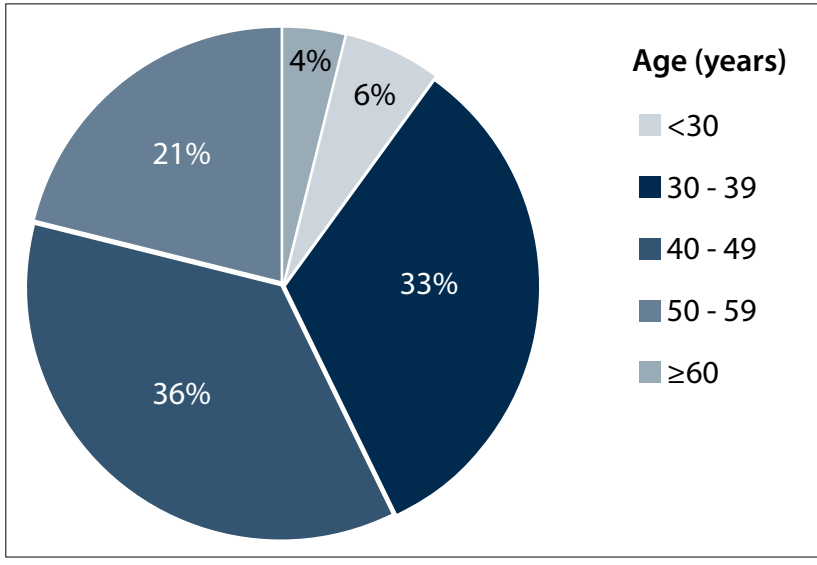

Fig. 1. Age distribution of the respondents.

(registrars) and medical officers. Forty-four (62\%) had received postgraduate training in burn care, whereas 55 (79\%) had learnt through practical hospital experience. Twenty-one respondents (30\%) had completed a burn care rotation during internship, and 43 (61\%) had completed a 3 - 6-month rotation at postgraduate level.

\section{Burn unit resources and activities}

The majority of units (85\%) had access to consultants. Only half the units had registrars (48\%) and interns (51\%) as part of the staff complement. Thirty percent of the respondents were dedicated to burn care, the majority being involved in burn care part time, being otherwise in trauma (42\%), plastic surgery (44\%) or general surgery $(48 \%)$. Involvement in duties other than clinical work included research (52\%) and education of doctors (60\%), nurses (44\%), physiotherapists (3\%) and medical students (39\%). Only $30 \%$ were involved in community outreach. Burn care was provided in a dedicated burn ward in $52 \%$ of respondents' hospitals. Working hours in burn care per week were on average 14 hours per week (range 0 - 120) in the ward, 7 hours (range 0 - 25) in theatre, 2.3 hours (range $0-20$ ) in the clinic and 2.9 hours (range $0-28$ ) in teaching. There was an expressed need for more staff on all levels, $58 \%$ needing registrars, $62 \%$ medical officers, $68 \%$ nurses and $58 \%$ allied health professionals.

Forty-seven percent of respondents were not training registrars at the hospital or institution at which they worked. The remaining respondents $(53 \%)$ trained registrars with rotations varying from 1 month (18\%) to 6 months (23\%). The majority opinion (72\%) was that a medical officer was skilled enough to work in the field of burns and that specialist training was not necessary.

\section{Attractions to a career in burn care}

Asked why they had become involved in burn care in SA, 54\% cited early exposure (as a student, intern or medical officer) to burn care and $39 \%$ exposure at a postgraduate level. Mentor influence during training was cited by $37 \%, 31 \%$ seeing burn care as a possible career path and $56 \%$ believing it to be a rewarding field (Fig. 2).

\section{Deterrents to a career in burn care}

Respondents cited emotional difficulties (75\%), a difficult working environment (70\%), lack of support (55\%) and the nature of the surgery $(51 \%)$ as key deterrents to working in the burn field. Poor prognosis (46\%), lack of training and skills development (35\%), poor remuneration $(30 \%)$ and lack of associated academic prestige (27\%) were other deterrents. Lack of teamwork and interest, longterm morbidity caused by burns and lack of recognition by hospital

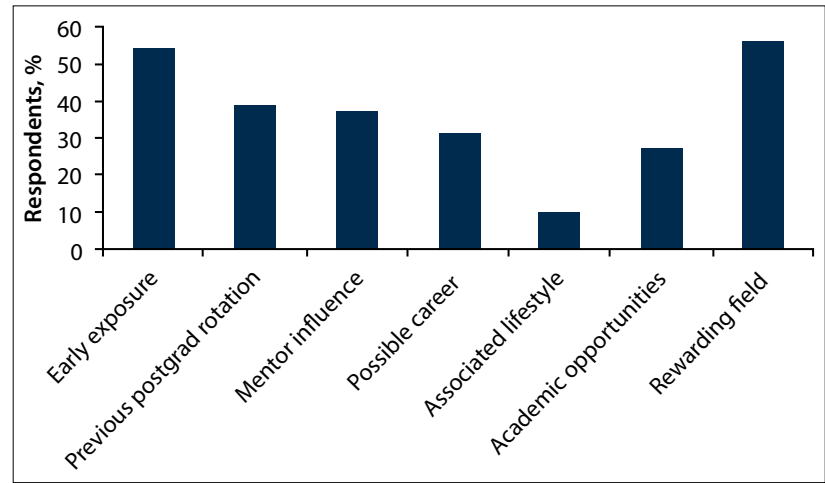

Fig. 2. Attractions to a career in burn care.

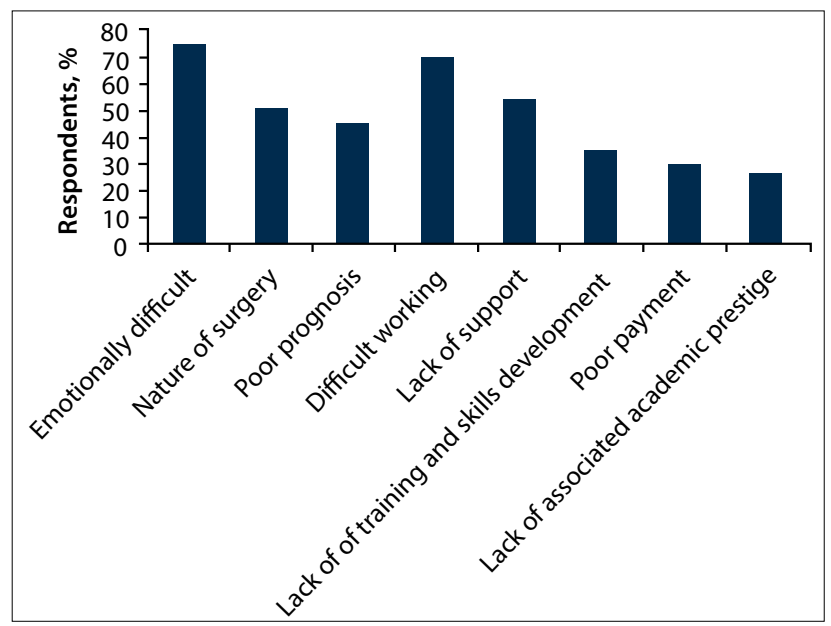

Fig. 3. Deterrents to a career in burn care.

management were further deterrents to entering the field of burn care as a profession (Fig. 3).

\section{Issues for workforce planning}

Better facilities and resources (76\%) was by far the most common factor that respondents suggested was needed to recruit future burn care providers (Fig. 4). Others included training and skills development (59\%), subspecialist training (55\%), a diploma in burn care (52\%), development of research (52\%), healthcare worker psychological support (45\%), better payment (44\%) and flexible working hours (39\%). Encouragement and adequate learning opportunities including seminars and courses, a change in mindset regarding burn care, better integration between departments at healthcare institutions, publicity of success stories to improve the image of burn care and clearer guidelines on management of burns were other strategies suggested.

\section{Discussion}

Burn care, encompassing an integrated and functional infrastructure staffed with appropriately trained personnel to provide adequate care for a patient with highly complex injuries, is associated with improved survival, decreased length of hospital stay and a reduction in costs. ${ }^{[7,8]}$

Burn care is viewed as a Cinderella-type, non-accredited specialty. There is a shortage of burn units, as defined by the American Burn Association, for large numbers of patients, and inadequate numbers of surgeons/medical officers to provide the services needed for prehospital care, acute care and post-burn rehabilitation. The deficit is even greater among professions allied to medicine. The 


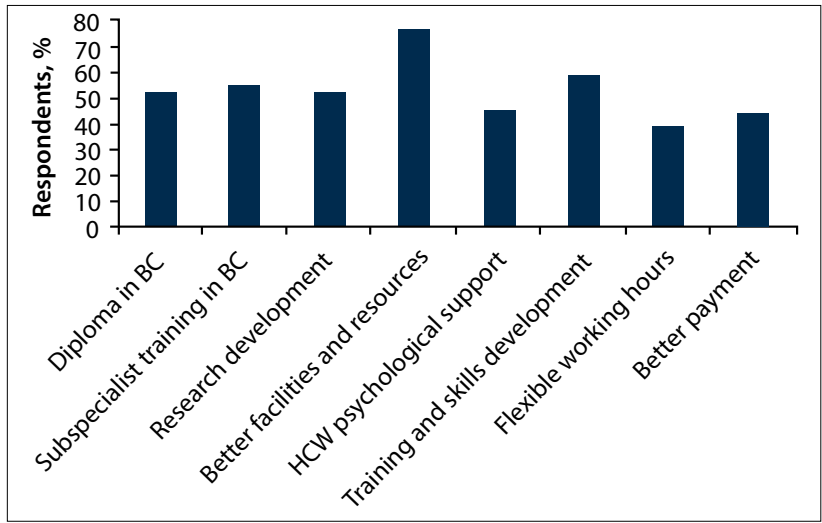

Fig. 4. Potential attractions to burn care. $(B C=$ burn care; $H C W=$ healthcare worker.)

skills needed to care for burn patients are diverse and include skills from general and plastic surgery as well as from critical care. This means that very often no single specialty will or can accept overall responsibility for the management of these complex cases, further compounding an already critical situation.

This survey has provided basic information towards workforce planning, which can be used to inform strategic decisions. The majority of doctors engaging in burn care are young, are not specialist surgeons, and are involved part time (with an average of only 16 hours per week). It was not clear from the survey whether the additional clinical workload of trauma, general and plastic surgery diluted time allocated to burn care. It may be that doctors prefer to have diverse interests or that the department they work in dictates additional responsibilities.

This survey emphasised the unattractiveness of a career in burn care. Many factors have been identified: burn surgery is not accredited as a specialty, there are no specific training programmes, experienced supervision is often deficient, there is a lack of career path development, facilities are often inadequate, fiscal restraints hamper progress, and academic standing is lacking. Burn surgery is not part of mainstream trauma management and is often seen as a separate and mainly unrelated, albeit essential, service. There is also the belief among surgeons and administrators that non-surgeons can treat major complex burns.

While burn care is a labour-intensive field with specific needs, less than half the respondents were managing their patients in a dedicated ward. Burn care facilities were often short-staffed, $60 \%$ of respondents expressing the need for more doctors, nurses and allied health professionals. Poor resource allocation and infrastructure, common in low- to middle-income countries, ${ }^{[6,9]}$ was the second most common deterrent to working in this field.

Nevertheless, remedial factors were identified that made working under these circumstances tolerable. Three-quarters of the respondents said that what encouraged them to carry on working in burn care was the alleviation of suffering, restoration of function, patient resilience, and the personal reward of observing long-term recovery and reintegration into society of patients after being severely burned. Additional factors were working with children, the need for burns specialists in the public sector, the challenging nature of burn care, a team ethos and the encouragement and inspiration provided by mentors. The emotional wellbeing of caregivers was conversely sadly neglected, it being imperative to ensure psychological support for healthcare professionals in burn care.

Can factors be identified and implemented from this survey to make burn care as a specialty more attractive? We have demonstrated that current workforce resources are inadequate, with the major deficit being lack of training and the resource-restricted, shortstaffed environment. As career choices are influenced by early clinical exposure, education (the theory and practice of burn care) and training should start at under- and postgraduate level with a compulsory rotation in burns for both interns and registrars. ${ }^{[3]}$ Skills development focusing on core knowledge and practical competencies should be the primary goals. Current burn surgeons are in a unique situation to act as mentors to their younger colleagues and could act as a catalyst to consideration of burn surgery as a career. ${ }^{[3,10]}$

With the small number of specialists in the field, sustainability of education and training would be a challenge. The use of modalities such as e-learning, career pathway development, fellowships and research and academic support are essential components. International collaboration with high-income countries providing support and expertise to address the surgical workforce crisis, as demonstrated in Malawi, ${ }^{[11]}$ could be an effective model in enhancing burn care locally.

Regular psychological support and team development are also needed to prevent compassion fatigue among staff working day after day with challenging cases. This would strengthen the pull factors towards working in and staying in burn care. National programmes need to be established. The creation of more training and consultant posts and improvement of infrastructure requires resource allocation and political will.

\section{Conclusion}

We have provided an overview of the current workforce resources and gaps in the field of burn care in SA. Key areas have been identified to achieve development of an action plan to close the gaps. Implementation of the plan, monitoring, evaluation and revision over time are steps toward capacity building in burn care.

\footnotetext{
References

1. Rode H, Rogers A, Adams S, et al. The dilemma of treating major burns in South Africa. S Afr Med J 2013;103(9):608-609. [http://dx.doi.org/10.7196/SAMJ.7361]

2. Rode H, Cox SG, Numanoglu A, Berg AM. Burn care in South Africa: A micro cosmos of Africa. Pediatr Surg Int 2014;30(7):699-706. [http://dx.doi.org/10.1007/s00383-014-3519-5]

3. Kahn SA, Goldman M, Daul, M, Lentz CW. The burn surgeon: An endangered species. Can exposure in medical school increase interest in burn surgery? J Burn Care Res 2011;32(1):39-45. [http://dx.doi. org/10.1097/BCR.0b013e318204b318]

Ortiz-Pujols SM, Thompson K, Sheldon GF, Fraher E, Ricketts T, Cairns BA. Burn care: Are there sufficient providers and facilities? Bull Am Coll Surg 2011;96(11):33-37.

5. Kelly E, Rogers SO Jr. Graduate medical education in trauma/critical care and acute care surgery: Defining goals for a new workforce. Surg Clin North Am 2012;92(4):1055-1064. [http://dx.doi. org/10.1016/j.suc.2012.04.006]

6. Gupta S, Wong EG, Mahmood U, Charles AG, Nwomeh BC, Kushner AL. Burn management capacity in low and middle-income countries: A systematic review of 458 hospitals across 14 countries. Int $J$ in low and middle-income countries: A systematic review of 458 hospitals
Surg 2014;12(10):1070-1073. [http://dx.doi.org/10.1016/j.ijsu.2014.08.353]

7. American Burn Association. Burn Incidence and Treatment in the United States: 2011 Fact Sheet. http://www.ameriburn.org/resources_factsheet.php (accessed 11 August 2015).

8. Sheridan RL. Burn care: Results of technical and organizational process. JAMA 2003;290(6):719-722. [http://dx.doi.org/10.1001/jama.290.6.719]

9. Calland JF, Holland MC, Mwizerwa O, et al. Burn management in sub-Saharan Africa: Opportunities for implementation of dedicated training and development of specialty centers. Burns 2014;40(1):157163. [http://dx.doi.org/10.1016/j.burns.2013.05.015]

10. Ellsbury KE, Carline ID, Irby DM, Stritter FT. Influence of third-year clerkships on medical student specialty preferences. Adv Health Sci Educ Theory Pract 1998;3(3):177-186.

11. Qureshi JS, Young S, Muyco AP, et al. Addressing Malawi's surgical workforce crisis: A sustainable paradigm for training and collaboration in Africa. Surgery 2013;153(2):272-281. [http://dx.doi. org/10.1016/j.surg.2012.08.004]
}

Accepted 14 October 2015. 


\section{Appendix 1}

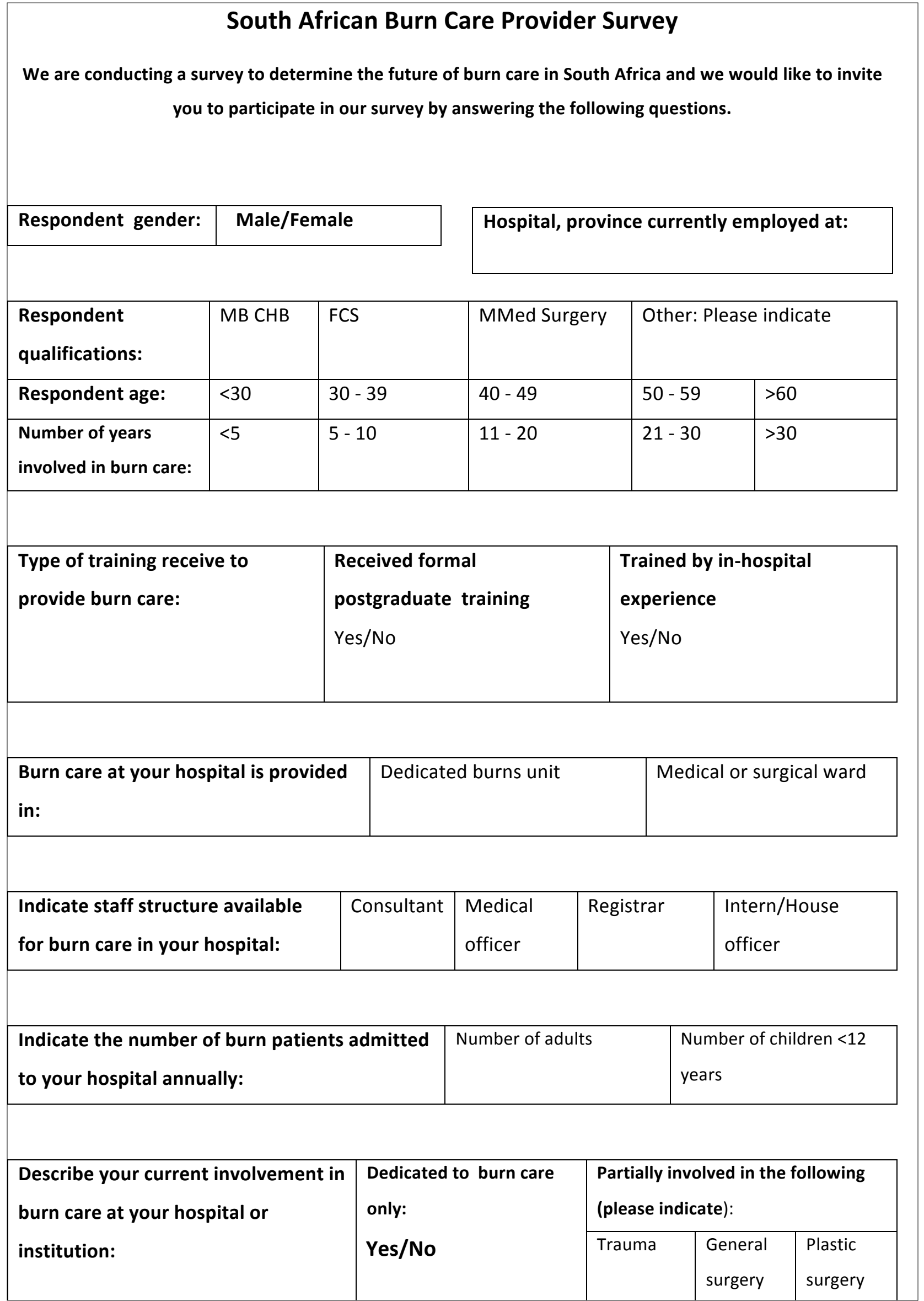




\begin{tabular}{|c|c|c|c|c|c|}
\hline \multirow{4}{*}{$\begin{array}{l}\text { Are you currently } \\
\text { involved in: }\end{array}$} & \multirow{4}{*}{ Research } & \multirow{4}{*}{$\begin{array}{l}\text { Community } \\
\text { outreach } \\
\text { programme }\end{array}$} & \multirow{4}{*}{$\begin{array}{l}\text { Education - } \\
\text { please } \\
\text { indicate which } \\
\text { of the } \\
\text { following: }\end{array}$} & \multicolumn{2}{|c|}{ Medical students } \\
\hline & & & & \multicolumn{2}{|l|}{ Doctors } \\
\hline & & & & \multicolumn{2}{|l|}{ Nurses } \\
\hline & & & & \multicolumn{2}{|c|}{ Other - please indicate } \\
\hline \multirow{7}{*}{$\begin{array}{l}\text { Why did you become } \\
\text { involved in burn care - } \\
\text { please indicate: }\end{array}$} & \multicolumn{4}{|c|}{ Early exposure to burn surgery } & \\
\hline & \multicolumn{4}{|c|}{ Completed a burn rotation during postgraduate training } & \\
\hline & \multicolumn{4}{|c|}{ Influenced by a mentor during training } & \\
\hline & \multicolumn{4}{|c|}{ Interested in burn care as a possible career } & \\
\hline & \multicolumn{4}{|c|}{ Lifestyle associated with burn care } & \\
\hline & \multicolumn{4}{|c|}{ Academic opportunities within burn care } & \\
\hline & \multicolumn{4}{|c|}{ Rewarding field to work in } & \\
\hline
\end{tabular}

\begin{tabular}{|l|l|l|l|l|}
\hline $\begin{array}{l}\text { How many hours do you } \\
\text { spend on burn care per week: }\end{array}$ & Hours in the ward & Hours in theatre & $\begin{array}{l}\text { Outpatient } \\
\text { clinics }\end{array}$ & Hours teaching \\
\hline
\end{tabular}

\begin{tabular}{|c|c|c|}
\hline $\begin{array}{l}\text { Do you have to be a surgeon, or can a medical } \\
\text { officer also do the work: }\end{array}$ & Must be a surgeon & Can be a medical officer \\
\hline
\end{tabular}

\begin{tabular}{|l|l|l|l||}
\hline \multicolumn{2}{|l||}{ Have you been training registrars in burn care: } & \multicolumn{2}{|l|}{ Yes/No } \\
\hline $\begin{array}{l}\text { If yes, indicate time devoted to } \\
\text { registrar training: }\end{array}$ & $1-3$ months & $3-6$ months & More than 6 \\
months
\end{tabular}

\begin{tabular}{|l|c|}
\hline Have you completed a burn rotation during your internship? & Yes /No \\
\hline Have you completed a burn rotation during your post-graduation & Yes/No \\
training? & \\
\hline
\end{tabular}

\begin{tabular}{|l|l|l|l|l|}
\hline What would your future staffing & Registrars & Medical officer & Nurses & Allied health \\
needs be (you can indicate more & & & & workers \\
than one option): & & & & \\
\hline
\end{tabular}


The nature of burn care at times makes it difficult to maintain momentum - what motivates you?

\begin{tabular}{||l|l|l|}
\hline \multirow{4}{*}{\begin{tabular}{l}
\multirow{4}{*}{$\begin{array}{l}\text { Reasons why } \\
\text { people do not } \\
\text { work in } \\
\text { burns: }\end{array}$} \\
\cline { 2 - 3 }
\end{tabular}} & Nature of the surgery & \\
\cline { 2 - 3 } & Difficult working environment - poor infrastructure, lack of resources & \\
\cline { 2 - 3 } & Lack of support & \\
\cline { 2 - 3 } & Lack of training and skills development & \\
\cline { 2 - 3 } & Poor remuneration & \\
\cline { 2 - 3 } & Lack of associated academic prestige & \\
\cline { 2 - 3 } & OTHER: please specify & \\
& & \\
\end{tabular}

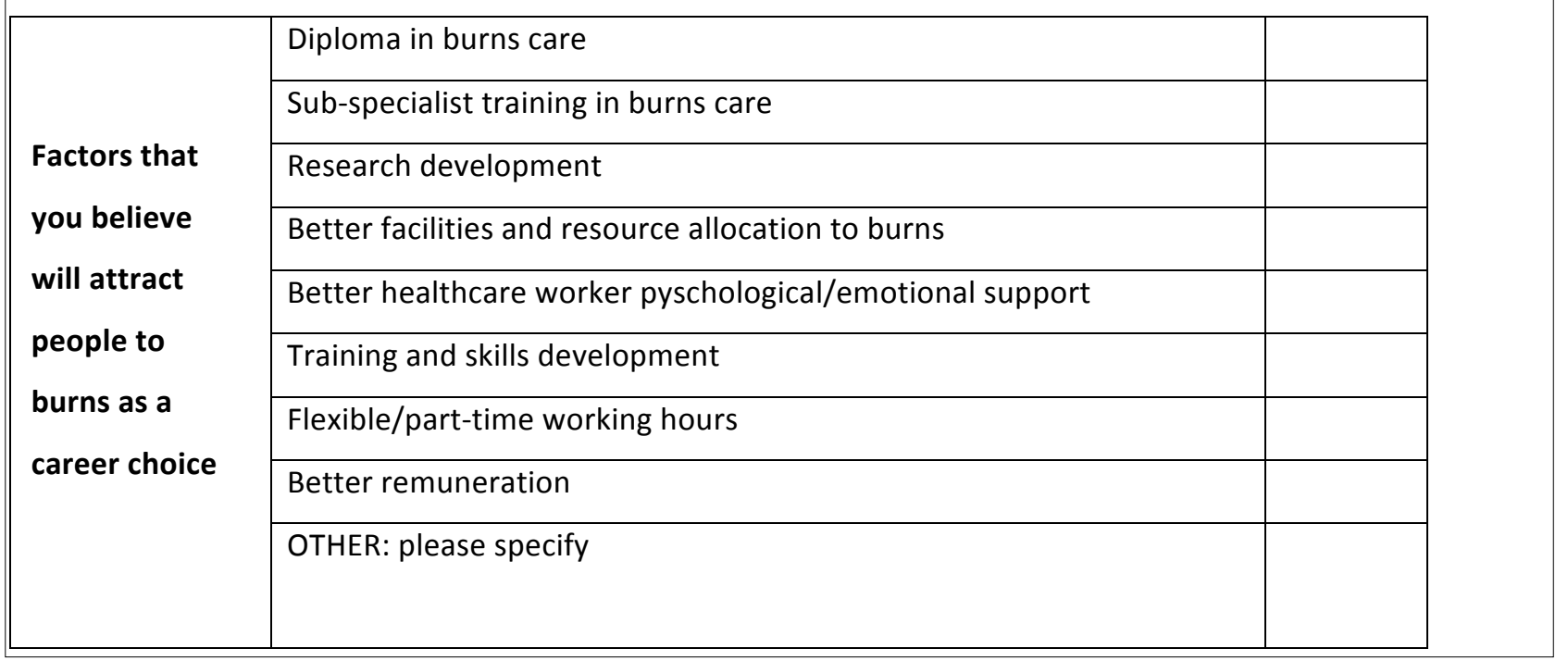

